\title{
Beyond Payoff Diagrams: How to Present Risk and Return Characteristics of Structured Products
}

\author{
Martin Wallmeier*
}

June 2011

\begin{abstract}
The market for structured products in Germany and Switzerland experienced a decade of rapid growth before the financial crisis. When Lehman Brothers went bankrupt, however, it became apparent that many private investors had not been aware of the risks involved in these certificates. There is evidence that the success of some of the most popular products was due to behavioral biases of investors. There is also concern that the complexity and diversity of the products was accompanied by low transparency. In practice, the information provided to investors is still often focused on payoff diagrams. For the future development of the market, it is important to improve investors' information and understanding. To this end, this paper analyzes the information requirements and proposes a risk and return survey to provide relevant and comprehensive information on market risk. Specifically, we propose to (1) illustrate the return probability distribution in three different ways, in particular a rolling dice analogy, (2) apply the Leland model to specify the risk and return tradeoff, and (3) include a specific measure of active risk. We illustrate these measures and information tools for a sample of stylized products.
\end{abstract}

JEL classification: G11; G14; G24

Keywords: Structured products, retail derivatives, risk measurement, risk-return tradeoff, investment decisions, information tools.

${ }^{*}$ Prof. Dr. Martin Wallmeier, Chair of Finance and Accounting, University of Fribourg, Switzerland, Bd. de Pérolles 90, CH-1700 Fribourg, martin.wallmeier@unifr.ch 


\section{Introduction}

The recent financial crisis has led to a critical view of many retail financial instruments and services. As a consequence, in the United States, a new office-called the Consumer Financial Protection Bureau-has been created to consolidate and strengthen consumer protection. The new regulation is primarily directed at the credit and mortgage markets. However, structured financial products outside loan markets were also caught up in the maelstorm of the financial crisis when Lehman Brothers went bankrupt in September 2008. Apparently, many investors had not been aware of the credit risk involved in these instruments. This clearly indicates that better customer advice and more transparency are required.

Structured products consist of two or more different asset components, one of which is a derivative (see Stoimenov and Wilkens, 2005). They are issued by banks and may be sold to private or institutional investors. The products can be traded on an organized exchange or directly with the issuing bank, which quotes bid and ask prices during the product's lifetime. In some European countries, particulary Germany and Switzerland, the market for these products grew rapidly during the decade before the financial crisis. The issuers work hard to design the products so that they will be very attractive to investors. In Germany and Switzerland, the regulatory environment offers the banks sufficient flexibility to quickly react to new market conditions and to create tailor-made investments. As a result, a number of innovations have been made and a large diversity of products is now available.

From a theoretical point of view, the market for structured products creates value by offering risk-return profiles that cannot be easily replicated by traditional financial instruments. On the one hand, structured products provide exposure to non-traditional asset classes such as commodities, to which investors might not have direct access. On the other hand, the payoff functions often have special characteristics, such as a minimum or maximum payoff and a nonlinear profile in between, which allow sophisticated investors to optimize their portfolios with regard to risk aversion, market expectations, and hedging concerns.

Practically speaking, however, actual product design and investor behavior challenge the view that structured products are "all good". In particular, some products appear to be overly complex. For instance, among the most popular instruments in the Swiss market are multiple barrier reverse convertibles (MBRC). The buyer of an MBRC is entitled to receive a fixed coupon payment on its face value, just like the buyer of a straight bond. In contrast to a bondholder, however, the buyer may receive assets instead of cash repayment of face value at maturity. The issuer of the MBRC has the right to "pay" with the worst-performing underlying asset, provided that at least one of the assets has crossed a downside barrier during the contract's duration. From an investor's point of view, this structure is equivalent to buying a straight bond and at the same time selling a multi-asset barrier put. In general, investors are reluctant to sell such a put option, as is apparent from the high market prices of out-of-the-money puts (see the typical "smile" or "skew" pattern of option-implied volatilities). It is also not clear how to integrate 
MBRC into portfolio planning because the buyer does not know in advance which stock will be delivered if the put is exercised. There is some evidence that investors typically underestimate the probability of hitting the barrier (see Rieger, 2011; Lindauer and Seiz, 2008). In addition, they generally seem to focus on the sure coupon and tend to neglect the fact that a high coupon is just one side of the coin, the other side being engraved high downside risk (see Wallmeier and Diethelm, 2009). Thus, investor behavioral biases seem important, and may indeed play a part in the design of structured products such that the products might be customized to take advantage of these behavioral biases.

There is also concern that the complexity and diversity of the products lead to low transparency. First, investors might find it difficult to understand all the relevant characteristics of complex products. Second, it is not always apparent where seemingly attractive returns come from. For instance, dividends of the underlying stocks are usually retained by the issuer. For this reason, the product will appear more attractive than a direct stock investment when only the payoff at maturity is considered. Third, valuing the more complex products is not straightforward. Since suitable pricing tools are not always publicly available, transparency with respect to fair values and their determinants might be poor, making it questionable whether competition between issuers is strong enough to ensure fair pricing. Empirical studies on the pricing of structured products in the primary market typically find a premium higher than theoretical values (overpricing) of about 2-6\%. ${ }^{1}$ For instance, a recent study on MBRC in Switzerland finds an average overpricing of about $3.5 \%$ on an annual basis ${ }^{2}$ (see Wallmeier and Diethelm, 2009, 2011). This price premium is highly relevant, but invisible, to investors. According to empirical studies, overpricing is more pronounced in less developed markets and positively related to the product's complexity.

There is broad consensus in financial theory and practice that the market for structured products requires well-informed investors who understand the product characteristics and the corresponding risk-return profiles. In Switzerland, an important information provider is the Swiss Structured Products Association (SSPA). Its "Swiss Derivative Map" categorizes available products, illustrates payoff functions, and provides an overview of the most important product features. Efforts are made to allow better comparisons between issuers. Detailed descriptions of structured products are available from most banks, and several institutions offer training on derivatives and structured products. In addition, the SSPA recently introduced a risk figure based on the valueat-risk (VaR) approach. Yet, other meaningful risk measures are not well established and rarely published. More importantly, the information actually provided to potential investors generally suffers from two main weaknesses: (1) it is typically focused on the payoff profile while neglecting

1 See Burth et al. (2001), Wilkens et al. (2003), Schenk and Wasserfallen (1996), Grünbichler and Wohlwend (2005), Stoimenov and Wilkens (2005), Hernandez et al. (2007), Szymanowska et al. (2007), Benet et al. (2006), Grünbichler and Wohlwend (2005), and the literature review in Wallmeier and Diethelm (2009).

2 The analyzed products had a time to maturity of about one year. In this sense, the overpricing of about $3.5 \%$ is a per annum value. 
the payoff probability, although probability information is indispensable for evaluating any product, and (2) the relevant risk has to be measured with respect to a well-diversified portfolio, and the risk-return relationship can be analyzed only in a portfolio setting. Although this portfolio aspect of investment decisions is of crucial importance, it is typically ignored when presenting structured products.

Against this background, the objective of this paper is to propose a set of instruments suitable for illustrating and measuring the risk-return characteristics of derivatives and, in particular, structured products. These information instruments can be combined in a risk-return survey that provides different perspectives on product characteristics and captures the risk and return profile more comprehensively than a single risk measure. The tools should be applicable to a wide range of structured products, including complex ones such as MBRC.

In Section 2, we briefly review the literature on how mode of presentation affects decisions under risk. Section 3 develops a conceptual framework for analyzing structured products and derives requirements for risk and return analyses. Section 4 introduces the set of structured products for which we illustrate the risk-return analyses. In Section 5, we present our survey of information tools. Section 6 concludes.

\section{Literature on presentation mode and investment decisions}

Many studies show that how an investment opportunity is presented can have a strong impact on investment decisions. For example, Benartzi and Thaler (2001) find that, in experiments, individuals tend to apply a naive diversification rule known as the " $1 / \mathrm{N}$ heuristic" when confronted with a set of funds from which to select a portfolio. The $1 / \mathrm{N}$ rule is applied regardless of whether stock or bond funds prevail. As a result, the asset allocation among stocks and bonds will depend on the set of funds offered. In another study, Benartzi and Thaler (1999) analyze myopic loss aversion, which is the aversion to short-term losses when the investment horizon is long-term. An important result of the study is that "this aversion to short-term losses can be overcome by providing the subjects with the explicit distribution of potential outcomes" ${ }^{3}$. The crucial point was to inform the participants about the aggregated, long-term return distribution instead of showing one-period returns. Klos et al. (2005) confirm and strengthen this finding in further experiments. They conclude that "computing, showing and discussing aggregated distributions may have the potential to avoid utility losses in asset allocation decisions" 4 .

According to the seminal experiments of Kahneman and Tversky (1979), individuals are generally loss averse in the sense that losses with respect to the current reference point are about twice as heavily weighted as gains. In view of this finding, the popularity of reverse convertibles

\footnotetext{
3 Benartzi and Thaler (1999, p. 380).

4 Klos et al. (2005, p. 1788).
} 
in the Swiss and German market is startling. According to prospect theory, investors should avoid the downside risk that is so important in these products (see Breuer and Perst, 2007). A possible explanation for this contradiction is that investors are not fully aware of the risk (see Hens and Rieger, 2008; Wallmeier and Diethelm, 2009). Thus, it is crucially important to provide information about the loss probability and other risk characteristics. Several studies in other areas of risk choices test whether it makes a difference if the underlying probability distribution is described only, shown graphically or experienced through sampling. 5 "Sampling" means that the test subject repeatedly draws from the relevant distribution to gain some knowledge about its shape. According to some studies, individuals who "experience" the outcome in this way tend to be more willing to bear the risk of a rare loss event than are individuals who were simply given a description of the risk (description-experience gap). ${ }^{6}$ However, Rakow et al. (2008) report that this observation may be due to biased sampling. When the relative frequency of the rare event in experience sampling is identical to the probability given in the description setting, the description-experience gap disappears. Thus, the "results provide no support for the claim that decisions from description and decisions from experience require separate descriptive theories" 7 .

Many studies show that individuals' risk perception can substantially deviate from objective risk measures such as loss probability (see, e.g., Klos et al., 2005). ${ }^{8}$ Not surprisingly, perceived risk is typically found to be a better predictor for decisions under risk. Risk perceptions might depend on the way information is provided. The information environment is also known to be related to biases, such as overconfidence.

Most of the experimental literature concentrates on simple lotteries; few studies examine the asset allocation between stocks and bonds (e.g., Haisley et al., 2010). There does not seem to be experimental evidence for investments in derivatives or structured products. Therefore, it is difficult to draw definite conclusions from this literature. However, previous research does at least agree on the importance of providing information about loss probabilities. It also supports the notion that return distributions should be based on the individuals' investment horizon instead of shorter periods. Finally, in view of recent research, the gap between description-based and experience-based decisions does not seem to be substantial. This is important because sampling is not practical for most structured products. For instance, a huge number of drawings would be necessary to obtain a useful estimate of the probability of hitting the downside barrier of barrier reverse convertibles. Our proposed information tools take these general insights into account.

5 See, e.g., Barron and Erev (2003), Hertwig et al. (2004), and Hau et al. (2008).

6 See, e.g., Hertwig et al. (2004), Hau et al. (2008), and the review in Rakow and Newell (2010).

7 Rakow et al. (2008, p. 168). See also Fox and Hadar (2006).

8 This is also true for financial advisors. For example, Eriksen and Kvaloy (2010) find that advisors' behavior is characterized by myopic loss aversion (MLA). Their degree of MLA is even stronger than was observed in a control group of students. 


\section{Conceptual framework}

\subsection{Motivations for using derivatives}

The use of derivatives, as opposed to a direct investment in the underlying asset, can be motivated by three reasons: hedging, optimization with respect to a specific utility function, and speculation.

When used for hedging purposes, derivatives offset the risk involved in a base portfolio. First, however, this risk has to be clearly identified before an appropriate hedging instrument can be chosen. Therefore, in designing an effective hedging strategy, information on the base portfolio and the specific hedging relationship is more important than a general risk-return classification of derivatives. This is why we do not concern ourselves with the hedging motive in this paper.

The second motive for using derivatives is to take account of specific characteristics of the investor's utility function. In general, the optimal portfolios of heterogeneous investors will not be equal to simple combinations of the risk-free asset and the market portfolio. For instance, investors who behave in line with the cumulative prospect theory of Kahneman and Tversky $(1979,1992)$ tend to strongly weight the small probability of extremely negative returns and will therefore be interested in products that provide protection against downside risk. ${ }^{9}$

For example, investor preferences can be characterized in terms of moments of the return distribution: expected return, volatility, skewness and kurtosis. Blümke (2009) proposes measuring these moment preferences by means of a questionnaire. The job of financial advisors or portfolio managers is then to find the optimal return distribution. To simplify matching return distributions to preferences, Blümke proposes classifying structured products into three categories: capital guaranteed (low volatility, right skewed, medium kurtosis), yield enhancement (medium volatility, left skewed, high kurtosis), and participation (high volatility, low skewness, low kurtosis).

The main weakness of this approach is that it does not take into account how volatility, skewness and kurtosis are priced in the market. For example, investors might typically prefer rightskewed return distributions. The overall market, however, provides symmetrical returns. In this situation, not all investors can realize their preferred return distribution. The competition for positive skewness will result in a higher price for portfolios with the desired property. Thus, the expected asset returns contain a skewness-related premium. Similarly, since most investors have a preference for low kurtosis and low downside risk, these characteristics will also be priced in

9 See Shefrin and Statman (1993). This is why discount certificates and reverse convertibles are not attractive to investors who apply cumulative prospect theory (see Breuer and Perst, 2007). 
market equilibrium. This means that investors face a tradeoff between high expected portfolio return and an attractive shape of the return distribution. ${ }^{10}$

In general, nothing can be said about an investor's optimal portfolio structure without taking the return premia into consideration. In the case of homogeneous investors, the premium for positive skewness would exactly offset the tendency to construct a portfolio with a positively skewed distribution. Therefore, to draw adequate conclusions for portfolio optimization, either the risk premium has to be explicitly considered or the investor's preferences have to be measured relative to other investors in the market. It is not clear how this could be done in practice.

Hens and Rieger (2008) express investor preferences in terms of utility functions and analyze the utility gain that can be achieved by deviating from a linear market exposure using structured products. One important result is that some of the most successful structured products cannot be optimal for rational investors as long as the utility function is concave. For utility functions typically used in economic models, the improvement for investors is small. Only when introducing partially non-concave functions is the utility gain noticeable, but it is still too small to compensate for transaction costs of structured products. Branger and Breuer (2008) report similar results for CRRA investors (see also Henderson and Pearson, 2009). This means that the success of structured products cannot be explained by the attempt to optimize the portfolio's payoff profile with respect to individual investor utility functions. Therefore, this motive for trading derivatives will not play much of a role in our paper.

The third reason for using derivatives is speculation, which means that trading activities are based on active forecasts. The objective of active management is to gain abnormal returns by exploiting mispricing in the market. In contrast, passive investors typically do not hold derivatives but a set of passively managed funds. In line with this view, structured products and derivatives are often regarded as satellite portfolios within the core satellite approach. This approach is based on the Treynor and Black (1973) model, which decomposes the optimal portfolio of an active investor into a passive core part and an active fund containing all assets for which mispricing has been identified. Within this framework, structured products are convenient flexible instruments for implementing an active strategy. This motive-speculation-is the main focus of this paper.

\footnotetext{
${ }^{10}$ An example of this tradeoff is volatility investments. At first sight, investing in volatility appears attractive since volatility movements are known to be negatively correlated with stock index returns. The return distribution is strongly skewed to the right, which is appealing for most investors. However, a closer look reveals that the return premium for this investment is strongly negative, more so than can be explained by theoretical asset pricing models (see Carr and Wu, 2009; Hafner and Wallmeier, 2007, 2008; Alexander and Korovilas, 2011). Thus, contrary to the intuition based on skewness and kurtosis, it would be optimal to sell rather than buy volatility exposure.
} 


\subsection{Holding period and wealth distribution}

We assume that investors follow a buy-and-hold strategy with a time horizon identical to the time to maturity of the structured product. One reason for this assumption is that structured products are not appropriate for high-frequency trading: the transaction costs would be too high, at least for the more complex products for which bid-ask spreads are often significant. The second reason is that the dynamic trading strategies of individual investors are diverse and unknown, so that it is impossible to derive a "representative" return distribution.

At the portfolio level, we apply the payoff distribution pricing model (PDPM) of Dybvig (1988a). This model assumes that investors only care about the distribution of terminal wealth. Their preferences are state independent, which means that it does not matter in which state of the world a given return with a given probability is realized. Therefore, if two portfolios depend on different risk factors but generate the same return distribution, the PDPM holds that investors attribute the same value to both.

Using the PDPM has important consequences for the characteristics of optimal investment strategies. Dybvig (1988b) and Cox and Leland (2000) prove that in a complete and frictionless (Black-Scholes) market, the least costly way to achieve a given terminal wealth distribution always consists of a path-independent payoff. Path-dependent options such as barrier products are cost inefficient and therefore suboptimal. More generally, Dybvig (1988b) shows that cost-efficient payoffs are necessarily monotonic in the state price. Consequently, in the BlackScholes setting, optimal payoffs are always non-decreasing functions of the underlying stock price (Bernard and Boyle, 2010). Bernard and Boyle (2010) derive an explicit representation of cost-efficient strategies. ${ }^{11}$

These results raise doubts about the benefit of complex, path-dependent structures for investors, which is why we will consider only path-independent payoff profiles in our illustrations. The proposed information tools, however, are not restricted to this class of products. Moreover, it is possible to add an inefficiency measure to our risk and return survey. ${ }^{12}$ We do not follow this route because a cost-inefficiency measure should be based on the portfolio payoff of investors rather than on the payoff of single products. ${ }^{13}$ For instance, a put option would be classified inefficient in a separate analysis, while it could be optimal as a hedging instrument.

\footnotetext{
11 The seminal work by Dybvig (1988b) and Cox and Leland (2000) is based on a market with one underlying asset. Bernard et al. (2010) show that path-dependent products are not optimal in a multidimensional BlackScholes market either. In a further extension, Vanduffel et al. (2009) present cost-inefficiency results in a Lévy setting.

12 I am grateful to Steven Vanduffel (Vrije Universiteit Brussel) for this remark. In an empirical application, Amin and Kat (2003) construct a measure of cost inefficiency to evaluate the performance of hedge funds.

${ }^{13}$ However, our measure of the degree of active orientation is based on a similar idea as a cost-inefficiency measure and also considers the portfolio context (see Section 5.3).
} 


\subsection{Risk measurement and risk-return tradeoff}

Due to non-normal return distributions, the mean-variance framework of balancing risk and return is not appropriate for derivatives and structured products. Higher moments of the return distribution such as skewness and kurtosis are relevant. To cover downside risk, value-at-risk $(\mathrm{VaR})$ is frequently proposed as a risk measure. However, as is well known, VaR suffers from serious shortcomings, one of the main ones being that the measure does not consider the size of losses higher than VaR. It highlights only one feature of the return distribution so that the same VaR can be obtained from strongly divergent shapes of the return distributions. As the neglected characteristics of the return distribution are believed to be important determinants of risk premia in the market, $\mathrm{VaR}$ is not an appropriate risk measure for studying the risk-return tradeoff. In addition, investors are not concerned about the VaR of isolated products but about a product's contribution to overall portfolio risk. In addition to these conceptual shortcomings, estimating VaR is often difficult due to model risk and parameter uncertainty. For these reasons, a more comprehensive risk assessment is necessary. Such could be a risk-return survey that fulfills the following requirements.

- Because the survey is not intended only for professional investors, the risk-return profile should be illustrated in a simple and easily interpretable way.

- The information content of payoff profiles is very limited. Any risk assessment has to be based on return probability distributions. Thus, these return distributions should be clearly illustrated.

- Theoretical and empirical studies in the field of behavioral finance show that investors often do not consider all relevant information in an unbiased way. To avoid the possibility that investors consider only the "pretty" side of the coin (e.g., coupon or maximal return), the survey should provide a balanced view of upside and downside potential.

- From a theoretical and practical point of view, the risk-return profile must be analyzed in market equilibrium. This implies that diversification within a broad portfolio is explicitly taken into account.

- The survey provides specific information for active investors who use structured products as a means of profiting from perceived mispricing in the market. This requirement is a consequence of our focus on active management (see Section 3.1).

It is evident that one single risk measure cannot meet all these requirements.

\section{Structured products}

To illustrate the different information tools, we choose the following subset of structured products where the numbers in parantheses refer to product type code according to the SVSP Swiss 
Derivative $\mathrm{Map}^{14}$ : uncapped capital protection (1100), capped capital protection (1120), capital protection with knock-out (1130), reverse convertible (1220), barrier reverse convertible (1230), bonus certificate (1320), twin-win certificate (1340), bear and bull tracker (1300), and call and put warrant (2100). Note that the references to the SVSP Swiss Derivative Map are indicative only: our products are chosen for purposes of illustration and are not meant to exactly replicate real products. One noteworthy difference between our list of products and those available in the real market is that we only consider European-type products. For example, the barrier condition of the barrier reverse convertible is only checked at maturity. ${ }^{15}$ Another difference is that we allow for a negative payout in the case of the bear tracker. This means that the investor has to make a supplemental payment if the underlying asset rises by more than $100 \%$. The corresponding strategy in practice would be to buy another bear tracker when the first is canceled before maturity at a value near zero. However, the information tools we propose are not limited to our illustration sample but can be applied to almost any payoff profile.

The parameters of our example products are given in Table 1.

----- Table 1 about here -----

With the parameters set out in Table 1, the initial fair values are close to but not equal to the net value of 1 . For better comparison, we adjust the number of products such that their initial fair value is $1 .{ }^{16}$ All graphs and figures are based on these adjusted values. The familiar payoff functions of our products are shown in Figure 1.

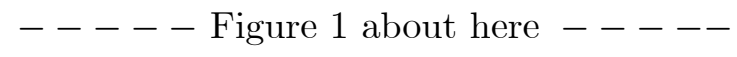

\section{Proposals}

\subsection{Return distribution}

It is common practice to characterize structured products by their payoff functions as in Figure 1. Payoff functions are shown in the SVSP Swiss Derivative Map as well as in many fact-sheets and advertisements. Yet, the payoff graphs only illustrate the magnitude of potential payoffs, without any information as to the probability of this occurrence. The probability information is important but often not intuitive. Therefore, it should become standard practice to show the

\footnotetext{
${ }_{14}$ See the description in Meier et al. (2010) and the website http://www.svsp-verband.ch.

15 One reason is that products with path-dependent payoffs are difficult to justify theoretically; see Section 3.2.

${ }^{16}$ For example, if the fair value is 0.95 , we assume that the investor buys $1 / 0.95$ products.
} 
return distribution in addition to the payoff profile. We present three different ways of doing this. ${ }^{17}$

\subsubsection{Return histogram and bar chart of ordered returns}

The first and most natural way to illustrate the return distribution is to plot a return histogram (for examples, see Blümke, 2009). The probability density function can be derived by historical simulation or Monte Carlo simulation (MCS). In historical simulation, the first step is to collect a sample of past relative changes in variables that determine the value of a structured product. These sets of movements serve as scenarios for the simulation. In the second step, a valuation model is used to compute the product's return for each of the historical scenarios. The frequency distribution of returns is then regarded as an approximation of the unobserved probability density function. MCS is different in that it starts from an analytical specification of the returngenerating process for the underlying assets. Based on this model, a large number of price paths is simulated. For each path, the payoff and return of the structured product can be calculated, which again results in a simulated return distribution.

The two methods are thoroughly compared in the literature (see, e.g., Jorion, 2007). One main weakness of historical simulation is that it considers only events that actually occurred in the past. In the case of MBRC, e.g., the result of historical simulation strongly depends on whether one of the underlying stocks suffered a sharp price decrease during the estimation period. Historical simulation is also limited to short horizons of a few days because, for longer horizons, there are not enough non-overlapping historical periods. To cover typical initial times to maturity of structured products (of about one to three years), an extrapolation of shortterm returns would be required to build historical scenarios. For these reasons, we do not use historical simulation.

The crucial point of MCS is to specify a realistic return-generating process. Many theoretical and empirical studies deal with the estimation of such processes based on historical data. In modeling stock returns, for instance, GARCH models capture important characteristics of stock return series, such as volatility clustering, which is why they have become a standard tool in finance. However, an accurate, fine-tuned return-generating model is far more important in option valuation than for our purpose of illustrating the shape of the probability density function. Therefore, in our examples, we apply the standard model of geometric Brownian motion. ${ }^{18}$ However, it is possible and straight-forward to generate similar graphs for more

\footnotetext{
${ }^{17}$ In a different approach, Rieger (2009) proposes a risk matrix based on three characteristics of the return distribution: the loss probability, the maximal loss, and the return potential.

18 This corresponds to the Black-Scholes framework, so that it is straight-forward to determine the initial values of the structured products.
} 
sophisticated processes. ${ }^{19}$

Figures 2 and 3 show the return distributions for our product sample. In Figure 2, the probability density functions are shown as return histograms. For means of comparison, the log-normal density of the underlying asset is included in each graph. ${ }^{20}$ It is apparent that the return histogram often provides interesting information not contained in the payoff diagram. For example, the downside risk of a barrier reverse convertible is clearly visible as a kind of counterbalance to the positive scenario of maximum return.

Figure 3 is based on a discretization of the return distribution into 50 equal parts so that each part represents a probability of $2 \%$. We compute the expected return for each part and plot these expected returns in ascending order. This form of presentation is sometimes used to show historical returns of an investment product. ${ }^{21}$ Its advantage is that each bar represents the same probability, so that it is not necessary to think in terms of probabilities to interpret the graph. The range of possible returns is clearly visible, and the profiles meaningfully reflect the specific characteristics of different products.

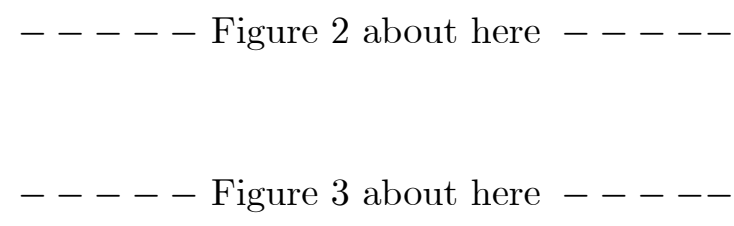

\subsubsection{Rolling dice analogy}

The insight that stock prices in informationally efficient markets follow a random walk is at the core of modern finance. This idea was first published by Louis Bachelier in 1900 and later formalized and elaborated by Fama (1970). It might still appear counter-intuitive to many investors that stock prices behave like a random walk when they are "correctly" based on fundamental data and rational expectations. However, sophisticated investors, financial advisors and portfolio managers are supposed to be familiar with this idea.

The random walk argument shows that investment products can be compared to lotteries. The analogy to lotteries makes sense only because the investor faces some inherent risk; it does not imply that investing is similar to gambling. We use a specific lottery with which every investor is familiar-playing dice-to present the risk-return profile of structured products. To

\footnotetext{
$\overline{19}$ See, e.g., Wallmeier and Diethelm (2011) for a comparison of the multivariate normal model with the variance gamma model which is based on a pure jump process. Röder and Wilkens (2003) consider reverse convertibles and discount certificates in the case of stochastic versus constant volatilities.

20 The horizontal axis in Figure 2 is defined as (1+discrete return). Therefore, the probability density function for the underlying asset is log-normal under geometric Brownian motion. It would be normal in a graph with continuously compounded returns on the horizontal axis.

21 See Beshears et al. (2009), Figures 4 and 5.
} 
this end, we divide the range of possible returns into 1/6-quantiles and compute the expected returns conditional on returns within the particular quantile. These expected quantile returns are ranked in ascending order and assigned the numbers on the dice. ${ }^{22}$

Formally, let $R$ be the random return of a structured product and $r$ a return realization over the investment horizon. Denote the probability density function by $f_{R}(r)$ and the cumulative distribution function by $F_{R}(r)$. The $p$-quantile $Q_{p}$ is defined as the smallest return that represents a cumulative probability of at least $p: Q_{p}=\inf \left\{r \mid F_{R}(r) \geq p\right\}, p \in(0,1)$. With the definitions $Q_{0}=0, Q_{1}=\infty$ and $p_{i}=i / 6, i=1, \ldots, 6$, the number $i$ of the dice is assigned the value:

$$
X(i)=E\left[R \mid Q_{p_{i-1}}<r \leq Q_{p_{i}}\right]=6 \int_{Q_{p_{i-1}}}^{Q_{p_{i}}} r \cdot f_{R}(r) d r .
$$

A financial advisor could explain the dice analogy to a client as follows.

An investment in this product involves some market risk. This means that the return over a one-year period is uncertain. The reason is that we do not know in advance if new information coming to the market in the future will be favorable or unfavorable for the asset. To get a better feeling of the risk involved, the following analogy might be helpful: the risk can be compared to rolling a dice where higher returns are paid out when the dice shows a higher number. The six possible returns in our asset dice are as follows: ....

One advantage of this approach is that it promises to countervail the tendency of investors to focus on the maximal return, e.g. the coupon of a reverse convertible. The return dice offers a balanced view because it reveals that high returns can be offered only if the investor is willing to bear an equally high risk of loss. This is apparent from Figure 4, which shows the return dice for our examples. For instance, in the case of the barrier reverse convertible, there is a good chance of gaining $8.5 \%$, but the investor can also see that she risks incurring a loss of $16 \%$.

----- Figure 4 about here -----

\subsection{Equilibrium risk-return tradeoff}

In financial markets, derivatives and structured products are priced as part of well-diversified portfolios. Therefore, the risk-return characteristics of these instruments can be determined only with respect to the market risk-return tradeoff. This tradeoff is often analyzed within the CAPM pricing model. While the standard version of the CAPM is not compatible with non-linear payoff profiles and therefore not applicable to options, Leland (1999) presents a modification of the

$\overline{{ }^{22} \text { In an analogous manner, the returns shown }}$ in Figure 3 can be interpreted as $1 / 50$-quantile returns. 
CAPM that does not require symmetrical return distributions. We propose to use this approach to analyze the risk-return tradeoff of structured products.

The model is based on research by Rubinstein (1976), Breeden and Litzenberger (1978), Brennan (1979), and He and Leland (1993). It assumes that the market portfolio follows a geometric Brownian motion so that market returns are log-normal. However, no assumption is made as to the return distribution of any risky asset included in the market. The model assumes that there is a representative investor with constant relative risk aversion. This implies that the representative investor is characterized by a risk-aversion coefficient equal to the market risk premium per unit of variance risk (for more detail, see the Appendix).

The main result of the Leland model is that a modified security market line holds for any risky asset $i$ regardless of its payoff profile:

$$
E\left[R_{i}\right]=R_{f}+\left(E\left[R_{M}\right]-R_{f}\right) \beta_{L}
$$

where $R_{f}$ is the one-period risk-free rate of return, $R_{M}$ is the market portfolio return and $R_{i}$ the return of asset $i{ }^{23}$ The modified beta is defined as:

$$
\beta_{L}=\frac{\operatorname{Cov}\left[-\left(1+R_{M}\right)^{-\alpha}, R_{i}\right]}{\operatorname{Cov}\left[-\left(1+R_{M}\right)^{-\alpha}, R_{M}\right]}
$$

where $\alpha$ is the risk aversion coefficient of the representative investor.

As can be seen from Equation (1), the security market line is still linear as in the standard CAPM. The only difference is that beta is replaced by a modified measure $\beta_{L}$ which is adapted to non-linear payout functions. The new beta measures the systematic risk of a product as part of the overall market and can be interpreted similarly to the standard CAPM.

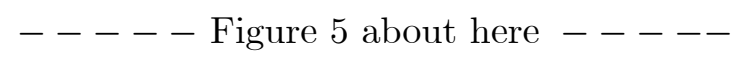

Figure 5 shows the Leland security line for the sample of products defined in Section 4 . As a general rule, the bearish products have a low or even negative expected return because of their inverse relationship to market movements (negative modified beta). The absolute value of beta is larger the more pronounced the product's leverage.

The Leland model has several attractive characteristics. First, risk is measured with respect to a well-diversified portfolio, which is essential but almost never considered in existing proposals for measuring derivatives' risk. Second, the risk measure is compatible with non-symmetrical return distributions and therefore applicable to all kinds of options. Third, the model allows illustrating the relationship between risk and return in the market and quantifying the specific

\footnotetext{
${ }^{23}$ Returns $R$ are defined as discrete (in contrast to continuously compounded) returns. See the Appendix for details.
} 
risk-return combination of each product. Fourth, there is an interesting link to the return dice proposed in the last section because the expected return is equal to the average of the six quantile returns. However, the dice presentation did not explain why the average returns differ across products. With the Leland model, these differences are naturally explained by different levels of systematic risk.

\subsection{Degree of active orientation}

The Leland model proposed in the previous section is based on a representative investor who, by definition, follows a passive strategy. As structured products are usually found in an active management domain, however, it is important to provide additional risk information for active investors. The objective is not to help investors generate valuable forecasts, but to make the degree of active orientation of portfolios more transparent.

Active investors will select structured products that, according to their private information, provide abnormal returns (alphas). These products serve as "satellites" around the passive core portfolio. If more weight is given to the satellites, the overall diversification is reduced and unsystematic risk increased. Therefore, investors face a tradeoff between diversifying (low specific risk, market-based returns) and aggressively exploiting positive "alphas" (higher specific risk, positive excess returns).

From the perspective of passive investors who do not have private information, an active portfolio looks suboptimal. As it deviates from the optimal portfolio structure, it implies a utility loss that is higher the more aggressive the active portfolio. This is why the utility loss can be interpreted as a measure of the degree of active orientation: it tells active investors how much, in terms of utility, they will lose if their superior forecasting ability turns out to be illusory.

To express potential utility loss in a meaningful way, we translate it into an equivalent loss of a proportion of initial wealth. The interpretation then is, for an investor without private information, that holding this (suboptimal) portfolio will provide the same expected utility as paying a one-time fee of $k \%$ of initial wealth and investing the remaining wealth in the optimal portfolio. The higher $k$ is, the better the forecasting ability of the active investor must be to offset the looming utility loss with positive abnormal returns.

Formally, let $S_{P}(t)$ denote the price of a structured product in which the portfolio manager invests the proportion $w$ of initial wealth $W(0)$. The remaining part $(1-w)$ is invested in the market portfolio. The expected utility based on the subjective probability measure $P_{a}$ of the active investor is:

$$
E_{P_{a}}\left[u\left(\frac{w W(0)}{S_{P}(0)} S_{P}(T)+\frac{(1-w) W(0)}{S_{M}(0)} S_{M}(T)\right)\right] .
$$

A passive investor (without superior forecasting ability) uses a different probability measure, denoted by $P_{p}$. From his perspective, the market portfolio will be optimal: it provides a higher 
expected utility than the active investor's portfolio:

$$
E_{P_{p}}\left[u\left(\frac{W(0)}{S_{M}(0)} S_{M}(T)\right)\right] \geq E_{P_{p}}\left[u\left(\frac{w W(0)}{S_{P}(0)} S_{P}(T)+\frac{(1-w) W(0)}{S_{M}(0)} S_{M}(T)\right)\right] .
$$

For each $w$, a parameter $k(w)$ can be uniquely determined such that:

$$
E_{P_{p}}\left[u\left(\left(1-\frac{k(w)}{100}\right) \frac{W(0)}{S_{M}(0)} S_{M}(T)\right)\right]=E_{P_{p}}\left[u\left(\frac{w W(0)}{S_{P}(0)} S_{P}(T)+\frac{(1-w) W(0)}{S_{M}(0)} S_{M}(T)\right)\right] .
$$

Thus, the utility loss induced by investing in the active investor's portfolio is equivalent to the loss of a fraction $k(w)$ (in percent) of initial wealth.

Table 2 shows the $k(w)$-values for proportions $w \in\{5 \%, 10 \%, 25 \%, 50 \%, 75 \%, 100 \%\}$ of initial wealth invested in one structured product. Clearly, $k$ is increasing in $w$. Its magnitude differs strongly between the products. Not surprisingly, the put and call option stands out as particularly risky. The bear tracker is found in third place because it provides an exposure opposite to the market. In our framework, this can be optimal only if the investor has a strong active orientation.

Other risk measures can be useful, too. As examples, Table 3 shows the volatility, the loss probability, and value-at-risk figures for our sample of products.

\section{Conclusion}

This paper starts from the observation that although transparency in the market for retail derivatives is important, it cannot be assumed. For example, many private investors in structured products were not aware of credit risk before Lehman Brothers went bankrupt. Detailed contract specifications are always available to investors, but investment decisions are typically made on the basis of limited information only. Standard practice is to explain the contract design, illustrate the payoff diagrams, and specify some risk measures typically based on the value-atrisk framework. Clearly, there is room for improvement. In particular, structured products should be presented and analyzed as part of a diversified portfolio. Furthermore, a useful risk and return assessment should be based on a market equilibrium analysis because characteristics of return distributions such as skewness and kurtosis can be evaluated only when taking the related risk premia into account. These requirements are typically not met in practice and are not adequately considered in proposals published to date. 
In this paper, we propose a risk and return survey for investors who use structured products in order to actively manage their portfolios. Note that we consider only market risk. Additional information on credit risk is, of course, required. Figure 6 illustrates the survey for a reverse convertible. Our main propositions can be summarized as follows.

- A balanced risk and return survey should illustrate the product characteristics from different perspectives. Therefore, it will contain several information tools.

- Experimental studies show that aggregation of returns is not intuitive and investors are often not able to translate a distribution of short-term returns into a distribution corresponding to their longer investment horizon. As structured products are generally not suitable for short-term trading, a horizon of 10 trading days as often used in banks' risk management does not seem to be a good choice. Risk and return should always be measured over the product's lifetime.

- We propose estimating the return distribution by Monte Carlo simulation and illustrate the result in three different ways: return histograms, bar charts of ordered returns, and an illustration of quantile expected returns in a rolling dice analogy. All three presentation modes could help investors avoid focusing only on seemingly attractive coupon payments.

- Risk and return have to be evaluated with respect to market equilibrium. We propose specifying the risk-return combination on the security market line of the Leland (1999) model.

- We propose a measure for the degree of active orientation of a portfolio that includes a structured product. This allows active investors to better assess the disadvantage of losing diversification when shifting the portfolio toward "positive alpha" instruments.

- Other risk measures such as value-at-risk and higher moments of the return distribution (skewness, kurtosis) can be appended.

We derive our proposals from a list of requirements that is based on (1) studies of investment behavior from the field of behavioral finance, (2) theoretical and empirical studies on structured products and (3) portfolio theory. However, for more specific recommendations, evidence is needed on how the proposed information tools would actually be used and interpreted by investors. For example, it is an open question how representation biases play out in this market segment. Experimental studies can help clarify how the perceived attractiveness of structured products depends on how the products' characteristics are presented. Haisley et al. emphasize this aspect for asset allocation decisions when they state that "[f] uture research should further explore different graphical presentation formats" (2010, p. 20). The proposals made in this paper could be a basis for such experiments. 
Acknowledgement I thank the anonymous referees for their helpful comments.

\section{References}

Alexander, C. and Korovilas, D. (2011). The Hazards of Volatility Diversification, Working Paper ICMA Centre, Henley Business School at Reading.

Amin, G. and Kat, H. (2003). Hedge fund performance 1990-2000: Do the "money machines" really add value?, Journal of Financial and Quantitative Analysis 38(2): 251-274.

Barron, G. and Erev, I. (2003). Small feedback-based decisions and their limited correspondence to description-based decisions, Journal of Behavioral Decision Making 16: 215-233.

Benartzi, S. and Thaler, R. (1999). Risk aversion or myopia? Choices in repeated gambles and retirement investments, Management Science 45: 364-381.

Benartzi, S. and Thaler, R. (2001). Naive diversification strategies in defined contribution saving plans, American Economic Review 91: 79-98.

Benet, B., Giannetti, A. and Pissaris, S. (2006). Gains from structured product markets: The case of reverse-exchangeable securities (RES), Journal of Banking and Finance 30(1): 111132 .

Bernard, C. and Boyle, P. (2010). Explicit Representation of Cost-Efficient Strategies, Working Paper University of Waterloo.

Bernard, C., Maj, M. and Vanduffel, S. (2010). Improving the Design of Financial Products in a Multidimensional Black-Scholes Market, Working Paper Universiteit Brussel.

Beshears, J., Choi, J., Laibson, D. and Madrian, B. (2009). Can Psychological Aggregation Manipulations Affect Portfolio Risk-Taking? Evidence from a Framed Field Experiment, Working Paper Harvard University, Yale University and NBER.

Blümke, A. (2009). How to Invest in Structured Products, Wiley.

Branger, N. and Breuer, B. (2008). The Optimal Demand for Retail Derivatives, Working Paper University of Münster.

Breeden, D. and Litzenberger, R. (1978). Prices of state-contingent claims implicit in option prices, Journal of Business 51: 621-651.

Brennan, M. (1979). The pricing of contingent claims in discrete time models, Journal of Finance 24: $53-68$.

Breuer, W. and Perst, A. (2007). Retail banking and behavioral financial engineering: The case of structured products, Journal of Banking and Finance 31(3): 827-844. 
Burth, S., Kraus, T. and Wohlwend, H. (2001). The pricing of structured products in the Swiss market, Journal of Derivatives 8(Winter): 30-40.

Carr, P. and Wu, L. (2009). Variance risk premiums, Review of Financial Studies 22: 1311-1341.

Cox, J. and Leland, H. (2000). On dynamic investment strategies, Journal of Economic Dynamics and Control 24: 1859-1880.

Dybvig, P. (1988a). Distributional analysis of portfolio choice, Journal of Business 61: 369-393.

Dybvig, P. (1988b). Inefficient dynamic portfolio strategies or how to throw away a million dollars in the stock market, Review of Financial Studies 1(1): 67-88.

Eriksen, K. and Kvaloy, O. (2010). Do financial advisors exhibit myopic loss aversion?, Financial Markets and Portfolio Management 24(2): 159-170.

Fama, E. (1970). Efficient capital markets: A review of theory and empirical work, Journal of Finance 25: 383-418.

Fox, C. and Hadar, L. (2006). "Decisions from experience" = sampling error + prospect theory: Reconsidering Hertwig, Barron, Weber and Erev (2004), Judgment and Decision Making 1: 159-161.

Grünbichler, A. and Wohlwend, H. (2005). The valuation of structured products: Empirical findings for the Swiss market, Financial Markets and Portfolio Management 19(4): 361380.

Hafner, R. and Wallmeier, M. (2007). Volatility as an asset class: European evidence, European Journal of Finance 13(7): 621-644.

Hafner, R. and Wallmeier, M. (2008). Optimal investments in volatility, Financial Markets and Portfolio Management 22: 147-167.

Haisley, E., Kaufmann, C. and Weber, M. (2010). How Much Risk Can I Handle? The Role of Experience Sampling and Graphical Displays on One's Investment Risk Appetite and Comprehension, Working Paper Yale School of Management and University of Mannheim.

Hau, R., Pleskac, T., Kiefer, J. and Hertwig, R. (2008). The description-experience gap in risky choice: The role of sample size and experienced probabilities, Journal of Behavioral Decision Making 21: 493-518.

He, H. and Leland, H. (1993). On equilibrium asset price processes, Review of Financial Studies 6: 593-617.

Henderson, B. and Pearson, N. (2009). The Dark Side of Financial Innovation, Working Paper George Washington University.

Hens, T. and Rieger, M. (2008). The Dark Side of the Moon: Structured Products from the Customer's Perspective, Working Paper University of Zurich. 
Hernandez, R., Lee, W. and Liu, P. (2007). An Economic Analysis of Reverse Exchangeable Securities-An Option-Pricing Approach, Working Paper University of Arkansas.

Hertwig, R., Barron, G., Weber, E. and Erev, I. (2004). Decisions from experience and the effect of rare events in risky choice, Psychological Science 15: 534-539.

Ingersoll, J. (1987). Theory of Financial Decision Making, Rowman and Littlefield Publishers. Jorion, P. (2007). Value at Risk, McGraw-Hill.

Kahneman, D. and Tversky, A. (1979). Prospect theory: An analysis of decision under risk, Econometrica 47(2): 263-291.

Kahneman, D. and Tversky, A. (1992). Advances in prospect theory: Cumulative representation of uncertainty, Journal of Risk and Uncertainty 5(4): 297-323.

Klos, A., Weber, E. and Weber, M. (2005). Investment decisions and time horizon: Risk perception and risk behavior in repeated gambles, Management Science 51: 1777-1790.

Leland, H. (1999). Beyond mean-variance: Performance measurement in a nonsymmetrical world, Financial Analysts Journal 55: 27-36.

Lindauer, T. and Seiz, R. (2008). Pricing (Multi-) Barrier Reverse Convertibles, Working Paper University of St. Gallen.

Meier, M., Vanini, P., Béguelin, P., Manser, D. and Wasescha, E. (2010). Die Welt der Strukturierten Produkte - Das Buch zur SVSP Swiss Derivative Map, Verlag Finanz und Wirtschaft.

Merton, R. (1969). Lifetime portfolio selection under uncertainty: The continuous-time case, Review of Economics and Statistics 51: 247-257.

Rakow, T., Demes, K. and Newell, B. (2008). Biased samples not mode of presentation: Reexamining the apparent underweighting of rare events in experience-based choice, Organizational Behavior and Human Decision Processes 106: 168-179.

Rakow, T. and Newell, B. (2010). Degrees of uncertainty: An overview and framework for future research on experience-based choice, Journal of Behavioral Decision Making 23: 1-14.

Rieger, M. (2009). Optionen, Derivate und strukturierte Produkte, Schäffer-Poeschel.

Rieger, M. (2011). Probability misestimation and preferences in financial investment decision, Journal of Behavioral Finance (to appear).

Röder, K. and Wilkens, S. (2003). Reverse convertibles and discount certificates in the case of constant and stochastic volatilities, Financial Markets and Portfolio Management 17(1): $76-102$.

Rubinstein, M. (1976). The valuation of uncertain income streams and the pricing of options, Bell Journal of Economics and Management Science 7: 407-425.

Schenk, C. and Wasserfallen, W. (1996). Portfolio insurance for the small investor in Switzerland, Journal of Derivatives 3(Spring): 37-43. 
Shefrin, H. and Statman, M. (1993). Behavioral aspects of the design and marketing of financial products, Financial Management 22(Summer): 123-134.

Stoimenov and Wilkens (2005). Are structured products "fairly" priced? An analysis of the German market for equity-linked instruments, Journal of Banking and Finance 29(12): 29712993.

Szymanowska, M., Horst, J. and Veld, C. (2007). Reverse Convertible Bonds Analyzed, Working Paper University of Rotterdam.

Treynor, J. and Black, F. (1973). How to use security analysis to improve portfolio selection, Journal of Business 46: 66-86.

Vanduffel, S., Chernih, A., Maj, M. and Schoutens, W. (2009). A note on the suboptimality of path-dependent pay-offs in Lévy markets, Applied Mathematical Finance 16(4): 315-330.

Wallmeier, M. and Diethelm, M. (2009). Market pricing of exotic structured products: The case of multi-asset barrier reverse convertibles in Switzerland, Journal of Derivatives 17(2): 5972 .

Wallmeier, M. and Diethelm, M. (2011). Multivariate downside risk: Normal versus variance gamma, Journal of Futures Markets (to appear).

Wilkens, S., Erner, C. and Röder, K. (2003). The pricing of structured products in Germany, Journal of Derivatives 10(Fall): 55-68. 


\section{Appendix: Leland model}

\section{Assumptions}

The modified CAPM proposed by Leland (1999) is based on the following assumptions:

1. Markets are frictionless and allow for continuous trading.

2. Uncertainty is modeled by a probability space $(\Omega, \mathcal{F}, \mathcal{P})$ with state space $\Omega$, filtration $\left\{\mathcal{F}_{t}, 0 \leq t \leq T\right\}$ and physical probability measure $\mathcal{P}$. Under this probability measure, the price $S_{M}$ of the market portfolio follows a geometric Brownian motion:

$$
\frac{d S_{M}(t)}{S_{M}(t)}=\mu d t+\sigma d B(t)
$$

where $\{B(t), t \geq 0\}$ is a standard Brownian motion. Note that no assumption is made on the return generating process of the risky assets that are contained in the market portfolio.

3. The risk free rate of return $r$ (continuously compounded) is constant.

4. There exists a representative investor such that prices are determined as if every investor had the same (representative) preferences. This assumption implies that in equilibrium, the representative investor holds the market portfolio. Therefore, the market price of risk $\theta$ is equal to:

$$
\theta=\frac{\mu-r}{\sigma}
$$

5. The representative investor exhibits constant relative risk aversion (CRRA), i.e. the utility function is given by

$$
u(C)=\left\{\begin{array}{ccc}
\frac{C^{1-\alpha}}{1-\alpha} & \text { for } & \alpha>0, \alpha \neq 1 \\
\ln (C) & \text { for } & \alpha=1
\end{array}\right.
$$

where $\alpha$ is a risk aversion coefficient. It follows that marginal utility is given by $u^{\prime}(C)=$ $C^{-\alpha}$.

\section{General optimality condition}

Due to the Black-Scholes setting of assumptions 1. to 3., the market is complete. Thus, each payoff function of a European path-independent option with the market portfolio as underlying asset can be replicated by following a self-financing trading strategy in the riskless bond and the market portfolio. Formally, there exists a unique state price process $\{\zeta(t, T)\}$ such that the price of an asset with payoff $V(T)$ is given by $V(t)=E_{P, t}[\zeta(t, T) V(T)], t \leq T$, where $E_{P, t}[\cdot]$ is the expectation under the physical measure based on the information set available at time $t$. The value $\zeta(0,0)$ is equal to 1 . We use $\zeta(t)$ as shortform for $\zeta(0, t)$. The expected value $E_{P, 0}[\zeta(t)]$ is equal to the price of a riskless asset with a time $t$ payout of 1 , thus: $E_{P, 0}[\zeta(t)]=e^{-r t}$. In the following we write $E_{P}[\cdot]$ without subscript $t$ for $t=0$. 
Let $W(t)$ be wealth at time $t$. Given initial wealth $W(0)$, the representative investor maximizes expected utility:

$$
\max _{W(T)} E_{P}[u(W(T))] \quad \text { s.t. } W(0)=E_{P}[\zeta(T) \cdot W(T)] .
$$

The solution of this optimization problem is well known. The investor chooses optimal wealth $W^{*}(T)$ such that the marginal utility per unit of state price is constant (Ingersoll (1987), p. 189):

$$
\lambda=\frac{u^{\prime}\left(W^{*}(T)\right)}{\zeta(T)}
$$

and initial wealth is fully invested:

$$
W(0)=E_{P}\left[\zeta(T) \cdot W^{*}(T)\right]
$$

The optimality condition (3) with budget constraint (4) characterizes the general solution of the optimization problem. The next step is to insert a more specific expression for $\zeta(T)$ which is valid under geometric Brownian motion (Black-Scholes model).

\section{State price density and optimality condition in the Black-Scholes setting}

In the Black-Scholes setting, the state price density is known to be:

$$
\zeta(t)=e^{-r t} \frac{d \mathcal{Q}}{d \mathcal{P}}=e^{-r t} e^{-\frac{1}{2} \theta^{2} t-\theta B_{t}},
$$

where $d \mathcal{Q} / d \mathcal{P}$ is the Radon-Nikodym derivative with the unique equivalent martingale measure $\mathcal{Q}$. According to geometric Brownian motion, we have:

$$
\frac{S_{M}(t)}{S_{M}(0)}=e^{\left(\mu-\frac{1}{2} \sigma^{2}\right) t+\sigma B_{t}}
$$

and thus:

$$
\left(\frac{S_{M}(t)}{S_{M}(0)}\right)^{-\frac{\theta}{\sigma}}=e^{-\frac{\theta}{\sigma}\left(\mu-\frac{1}{2} \sigma^{2}\right) t-\theta B_{t}} .
$$

Using (6), the state price density (5) can be rewritten as:

$$
\zeta(t)=k \cdot S_{M}(t)^{-\frac{\theta}{\sigma}}
$$

where $k$ is the constant $k=e^{-r t} e^{-\frac{1}{2} \theta^{2} t+\frac{\theta}{\sigma}\left(\mu-\frac{1}{2} \sigma^{2}\right) t} S_{M}(0)^{\frac{\theta}{\sigma}}$. Thus, we can finally reformulate (3) as:

$$
c=\frac{u^{\prime}\left(W^{*}(T)\right)}{S_{M}(T)^{-\frac{\theta}{\sigma}}}
$$


with $c$ an appropriately scaled constant. Using assumption 5. (CRRA utility), we obtain:

$$
\begin{gathered}
c=\frac{W^{*}(T)^{-\alpha}}{S_{M}(T)^{-\frac{\theta}{\sigma}}} \\
\Longleftrightarrow W^{*}(T)=c^{-\frac{1}{\alpha}} S_{M}(T)^{\frac{1}{\alpha} \frac{\theta}{\sigma}} .
\end{gathered}
$$

The optimal payoff profile according to (9) can be interpreted as the payoff of a European power call option on the market portfolio with zero strike (Bernard et al. (2010), p. 13). In equilibrium, the market portfolio itself must be optimal, which means that the representative investor exhibits risk aversion of degree $\alpha_{*}:^{24}$

$$
\frac{1}{\alpha_{*}} \frac{\theta}{\sigma}=1 \Longleftrightarrow \alpha_{*}=\frac{\theta}{\sigma}
$$

Inserting (10) into (9), we obtain:

$$
W^{*}(T) \propto S_{M}(T) .
$$

Thus, terminal wealth is proportional to terminal market value, which means that the optimal portfolio of the representative investor is indeed equal to the market portfolio.

\section{Implications for asset pricing}

The last step consists of deriving the implications of this result for asset pricing. For any asset $i$ with payoff $H_{i}(T)$ we have:

$$
\begin{aligned}
H_{i}(0) & =E_{P}\left[\zeta(T) \cdot H_{i}(T)\right] \\
& =E_{P}[\zeta(T)] \cdot E_{P}\left[H_{i}(T)\right]+\operatorname{Cov}\left[\zeta(T), H_{i}(T)\right] \\
& =e^{-r T} E_{P}\left[H_{i}(T)\right]+\operatorname{Cov}\left[\zeta(T), H_{i}(T)\right] .
\end{aligned}
$$

In returns notation, this corresponds to:

$$
E\left[1+R_{i}\right] \equiv \frac{E_{P}\left[H_{i}(T)\right]}{H_{i}(0)}=\left(1-\operatorname{Cov}\left[\zeta(T), R_{i}\right]\right) e^{r T} .
$$

Thus:

$$
E\left[R_{i}\right]-\left(e^{r T}-1\right)=-\operatorname{Cov}\left[\zeta(T), R_{i}\right] e^{r T} .
$$

Rewriting (7) as $\zeta(t)=x\left(1+R_{M}\right)^{-\frac{\theta}{\sigma}}$, where $x$ is a constant and $1+R_{M}$ is defined as $S_{M}(t) / S_{M}(0)$, we obtain:

$$
E\left[R_{i}\right]-\left(e^{r T}-1\right)=x e^{r T} \operatorname{Cov}\left[-\left(1+R_{M}\right)^{-\frac{\theta}{\sigma}}, R_{i}\right] .
$$

$\overline{24}$ This was already shown by Merton (1969). 
This equation also holds for the market portfolio:

$$
E\left[R_{M}\right]-\left(e^{r T}-1\right)=x e^{r T} \operatorname{Cov}\left[-\left(1+R_{M}\right)^{-\frac{\theta}{\sigma}}, R_{M}\right] .
$$

Thus, combining (11) with (12) and defining $R_{f}=e^{r T}-1$, we obtain the modified security market line of the Leland model:

$$
\begin{aligned}
E\left[R_{i}\right] & =R_{f}+\left(E\left[R_{M}\right]-R_{f}\right) \frac{\operatorname{Cov}\left[-\left(1+R_{M}\right)^{-\frac{\theta}{\sigma}}, R_{i}\right]}{\operatorname{Cov}\left[-\left(1+R_{M}\right)^{-\frac{\theta}{\sigma}}, R_{M}\right]} \\
& =R_{f}+\left(E\left[R_{M}\right]-R_{f}\right) \beta_{L} .
\end{aligned}
$$



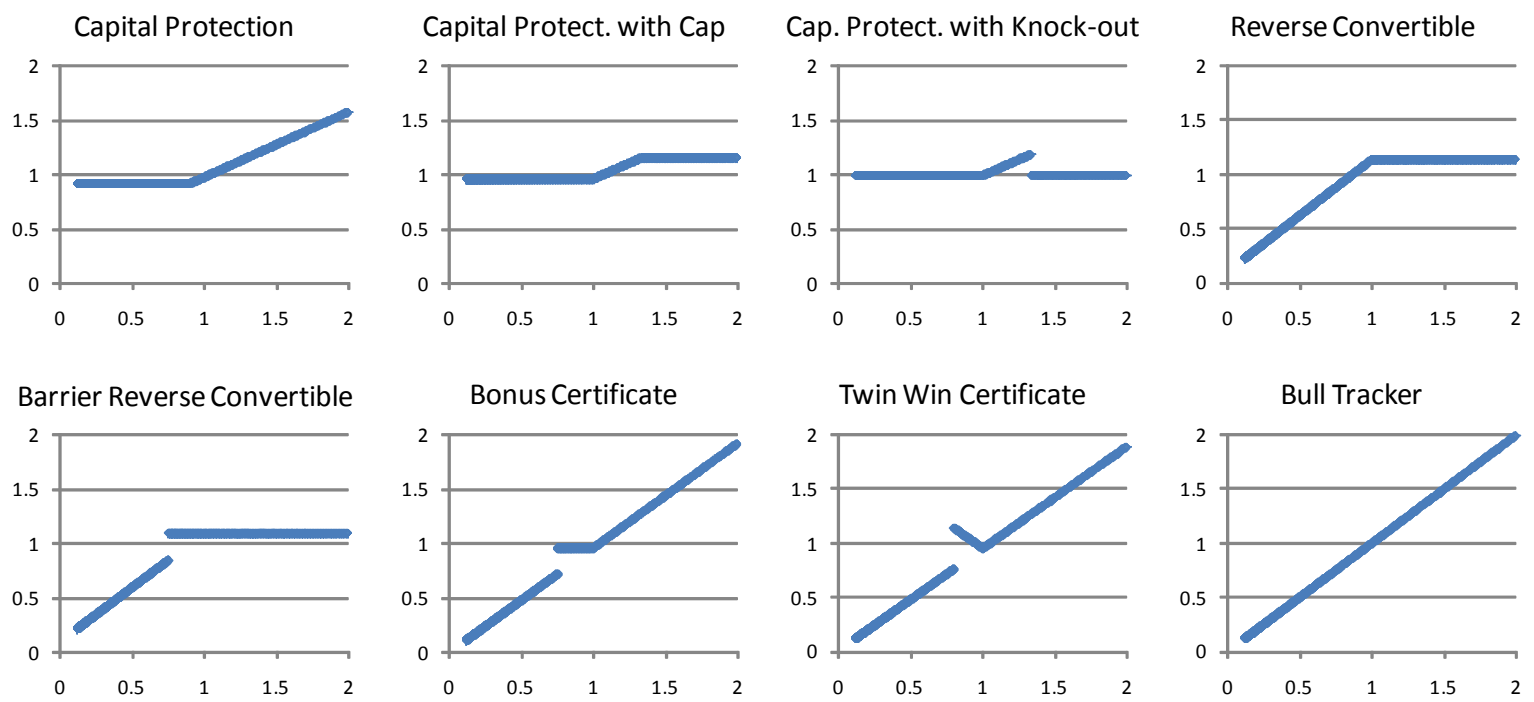

Bear Tracker

Call
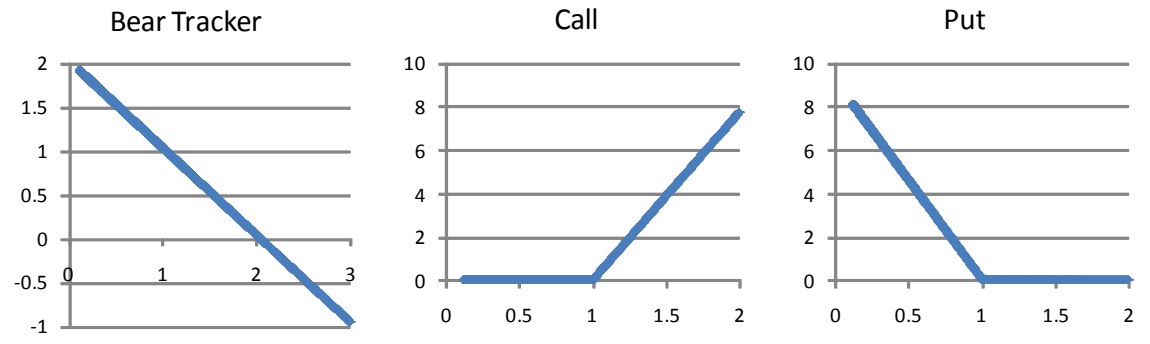

The graphs show the payoff at maturity (y-axis) with respect to the price of the underlying stock at maturity ( $x$-axis). The investment amount is standardized to 1 . The parameters are given in Table 1.

Figure 1: Payoff functions. This form of presentation was inspired by and is similar to the SVSP Swiss Derivative Map. However, we emphasize that the SVSP Swiss Derivative Map is more elaborate and contains further information. The parameters of our exemplary products are given in Table 1. 

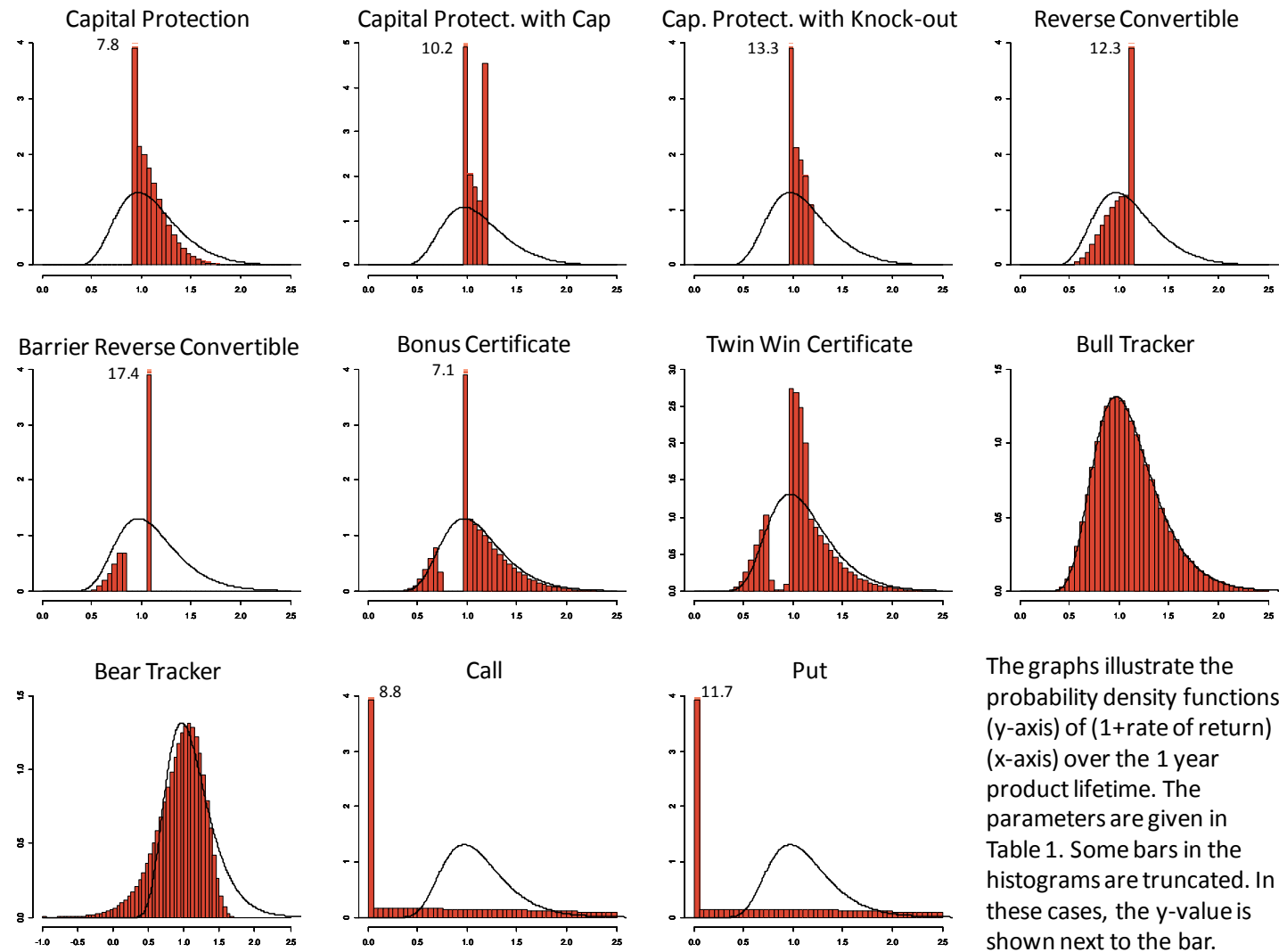

The graphs illustrate the probability density functions ( $y$-axis) of (1+rate of return) ( $x$-axis) over the 1 year product lifetime. The parameters are given in Table 1. Some bars in the histograms are truncated. In these cases, the $y$-value is shown next to the bar.

Figure 2: Return distributions. The probability density functions of returns from investing in a structured product are shown as return histograms (red bars). For means of comparison, the log-normal density of returns of the underlying asset is included (black lines). 

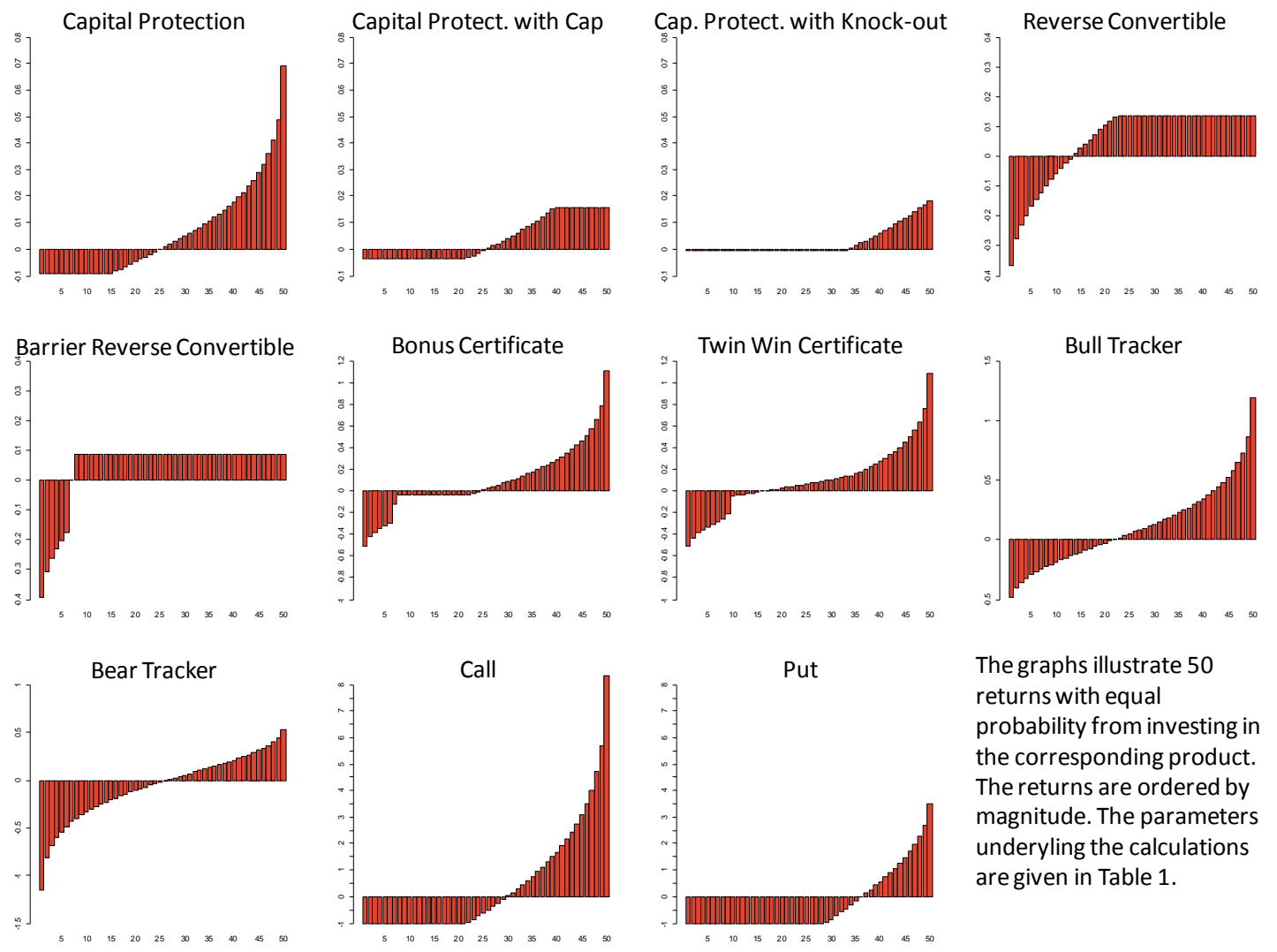

The graphs illustrate 50 returns with equal probability from investing in the corresponding product. The returns are ordered by magnitude. The parameters underyling the calculations are given in Table 1.

Figure 3: Ordered returns with equal probability. The charts are based on a discretization of the return distribution into 50 equal segments so that each segment represents a probability of $2 \%$. We compute the expected return for each segment and plot these expected returns in ascending order. 


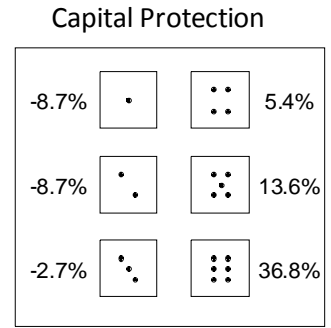

Barrier Reverse Convertible

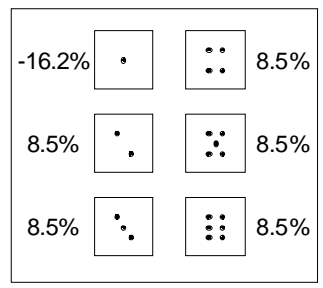

Bear Tracker

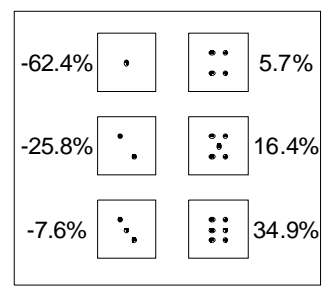

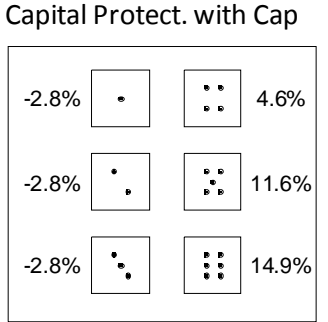

Bonus Certificate

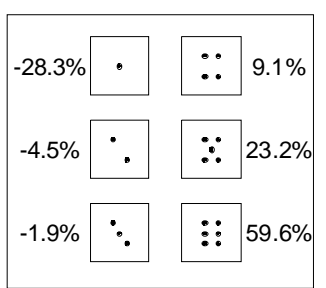

Call

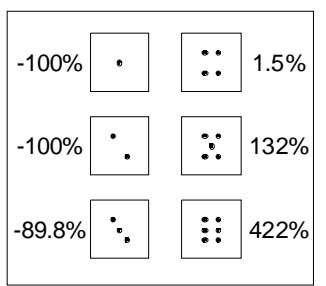

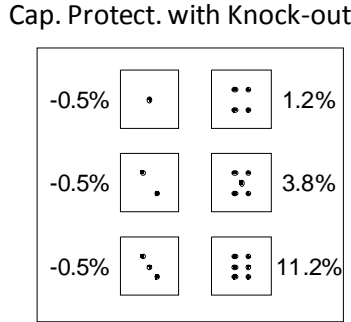

Twin Win Certificate

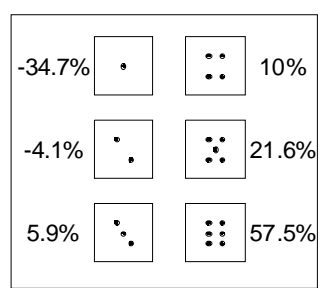

Put

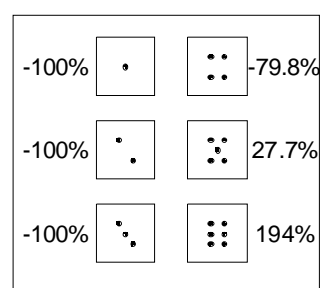

Reverse Convertible

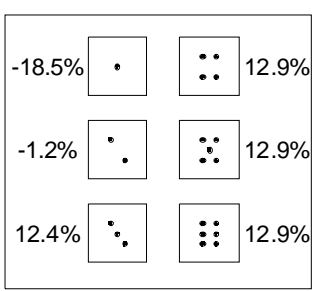

Bull Tracker

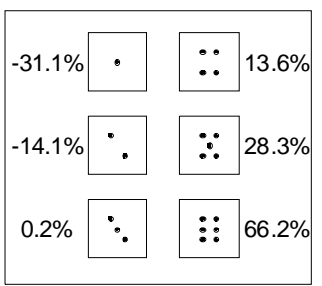

The illustrations show the expected returns within 1/6-return quantiles. Returns are measured over the 1 year product lifetime. The product parameters are given in Table 1.

Figure 4: Return dices. We divide the range of possible returns into 1/6-quantiles and compute the expected returns conditional on returns falling within the particular quantile. These expected quantile returns are ranked in ascending order and assigned to the numbers on the dice. 


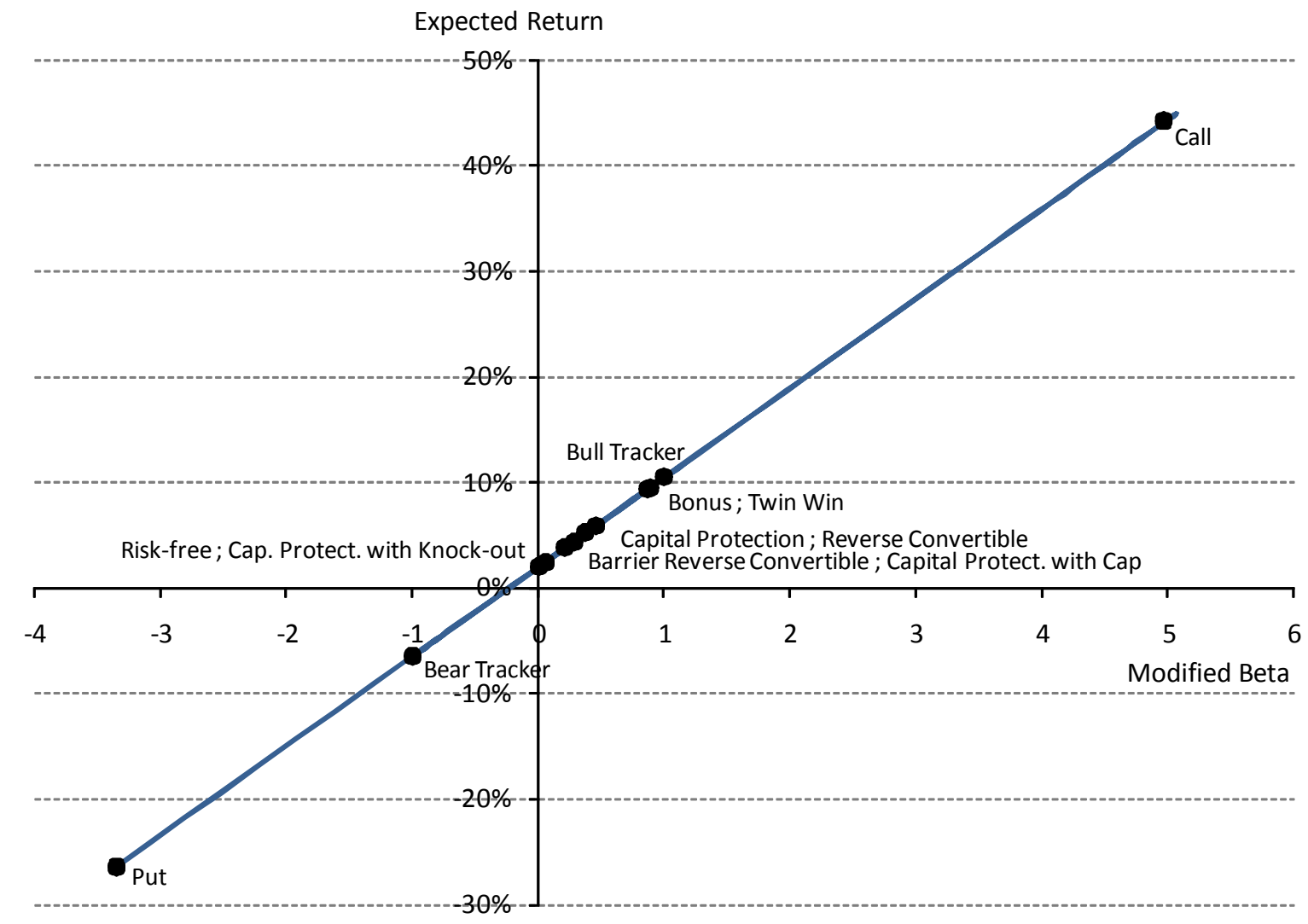

Figure 5: Security market line in the Leland modified CAPM 


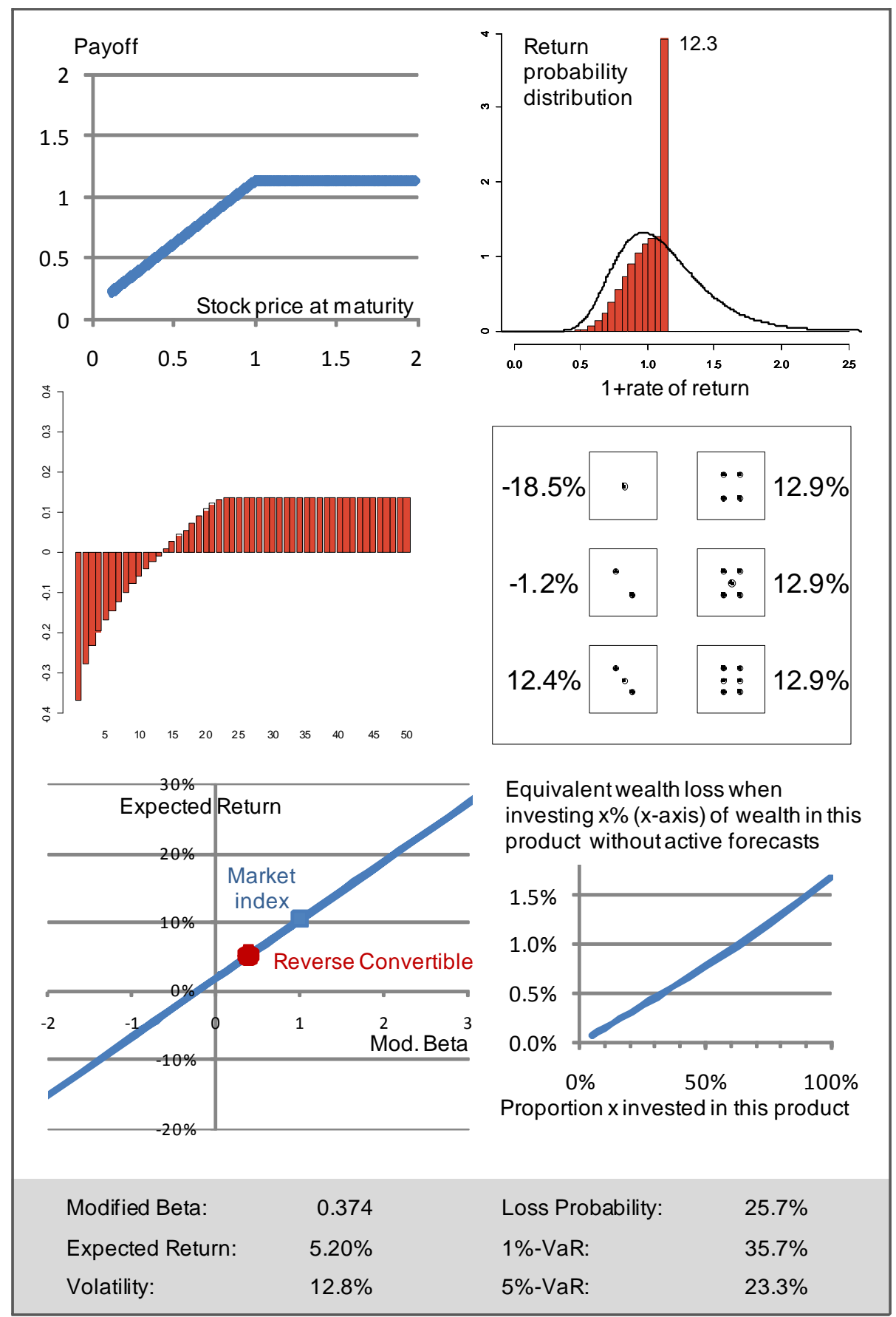

Figure 6: Risk return survey for a reverse convertible. Important note: This map only covers market risk. Credit risk has to be analyzed separately. 


\begin{tabular}{|c|c|}
\hline \multicolumn{2}{|l|}{ General parameters: } \\
\hline \multicolumn{2}{|l|}{ Nominal value: $N=1$} \\
\hline \multicolumn{2}{|c|}{ Initial price of the underlying stock: $S_{0}=1$} \\
\hline \multicolumn{2}{|c|}{ Instantaneous rate of return of the underlying stock: $\mu=10 \%$} \\
\hline \multicolumn{2}{|c|}{ Stock return volatility: $\sigma=30 \%$} \\
\hline \multicolumn{2}{|c|}{ Risk-free rate of return (continuously compounded): $r_{f}=2 \%$} \\
\hline \multicolumn{2}{|c|}{ Time to maturity: $T=1$} \\
\hline \multicolumn{2}{|l|}{ Strike price: $X=1$} \\
\hline \multicolumn{2}{|l|}{ Product specific parameters: } \\
\hline Uncapped capital protection (1100) & $\begin{array}{l}\text { Protection level } 90 \% \text { of nominal } \\
\text { Participation rate } 60 \%\end{array}$ \\
\hline Capped capital protection (1120) & $\begin{array}{l}\text { Protection level } 100 \% \text { of nominal } \\
\text { Cap } 1.2 \text { (maximal payout) } \\
\text { Participation rate } 60 \% \text { in between }\end{array}$ \\
\hline Capital protection with knock-out (1130) & $\begin{array}{l}\text { Protection level } 100 \% \text { of nominal } \\
\text { Knock-out (stock price level) } 1.3333 \\
\text { Participation rate } 60 \%\end{array}$ \\
\hline Reverse convertible (1220) & Coupon $10 \%$ \\
\hline Barrier reverse convertible $(1230)$ & Barrier 0.75 \\
\hline Bonus certificate $(1320)$ & Barrier 0.75 \\
\hline Twin-win certificate (1340) & Barrier 0.8 \\
\hline
\end{tabular}

Table 1: Parameters of products used for illustration. Figures 1 to 6 and Tables 2 and 3 are based on these parameters. 


\begin{tabular}{lrrrrrr}
\hline & $\mathbf{5 \%}$ & $\mathbf{1 0 \%}$ & $\mathbf{2 5 \%}$ & $\mathbf{5 0 \%}$ & $\mathbf{7 5 \%}$ & $\mathbf{1 0 0 \%}$ \\
\hline Capital Protection & $0.08 \%$ & $0.16 \%$ & $0.38 \%$ & $0.72 \%$ & $1.04 \%$ & $1.34 \%$ \\
Capital Protection with Cap & $0.14 \%$ & $0.27 \%$ & $0.66 \%$ & $1.28 \%$ & $1.88 \%$ & $2.49 \%$ \\
Capital Protection with Knock-out & $0.18 \%$ & $0.37 \%$ & $0.90 \%$ & $1.78 \%$ & $2.67 \%$ & $3.61 \%$ \\
Reverse Convertible & $0.07 \%$ & $0.15 \%$ & $0.38 \%$ & $0.78 \%$ & $1.21 \%$ & $1.69 \%$ \\
Barrier Reverse Convertible & $0.11 \%$ & $0.22 \%$ & $0.55 \%$ & $1.12 \%$ & $1.72 \%$ & $2.37 \%$ \\
Bonus Certificate & $0.01 \%$ & $0.03 \%$ & $0.07 \%$ & $0.13 \%$ & $0.19 \%$ & $0.25 \%$ \\
Twin Win Certificate & $0.07 \%$ & $0.06 \%$ & $0.14 \%$ & $0.27 \%$ & $0.39 \%$ & $0.50 \%$ \\
Bull Tracker & $0.00 \%$ & $0.00 \%$ & $0.00 \%$ & $0.00 \%$ & $0.00 \%$ & $0.00 \%$ \\
Bear Tracker & $0.82 \%$ & $1.62 \%$ & $3.95 \%$ & $7.84 \%$ & $\mathrm{NA}$ & $\mathrm{NA}$ \\
Call & $3.00 \%$ & $5.84 \%$ & $13.75 \%$ & $26.53 \%$ & $41.70 \%$ & $98.93 \%$ \\
Put & $6.62 \%$ & $12.05 \%$ & $24.84 \%$ & $41.67 \%$ & $58.46 \%$ & $99.95 \%$ \\
\hline
\end{tabular}

Table 2: Measure of degree of active orientation. From the perspective of passive investors without private information, an active portfolio looks suboptimal. As it deviates from the optimal portfolio structure, it implies a utility loss which is higher the more aggressive the active portfolio is. We translate this utility loss into an equivalent loss of a proportion of initial wealth. The first row specifies the weight of the structured product in the overall portfolio. The remaining amount is invested into the market index. 


\begin{tabular}{lrrrrr}
\hline & Volatility & Loss prob. & 1\%.VaR & $5 \%$-VaR & $10 \%$-VaR \\
\hline Capital Protection & $17.71 \%$ & $49.14 \%$ & $9.15 \%$ & $9.15 \%$ & $9.15 \%$ \\
Capital Protection with Cap & $8.10 \%$ & $50.25 \%$ & $3.50 \%$ & $3.50 \%$ & $3.50 \%$ \\
Capital Protection with Knock-out & $5.45 \%$ & $66.01 \%$ & $0.72 \%$ & $0.72 \%$ & $0.72 \%$ \\
Reverse Convertible & $12.85 \%$ & $25.73 \%$ & $35.68 \%$ & $23.33 \%$ & $15.68 \%$ \\
Barrier Reverse Convertible & $11.80 \%$ & $12.68 \%$ & $38.31 \%$ & $26.47 \%$ & $19.13 \%$ \\
Bonus Certificate & $30.45 \%$ & $48.02 \%$ & $49.70 \%$ & $38.21 \%$ & $31.08 \%$ \\
Twin Win Certificate & $30.31 \%$ & $31.76 \%$ & $50.36 \%$ & $39.02 \%$ & $31.99 \%$ \\
Bull Tracker & $33.92 \%$ & $42.48 \%$ & $47.62 \%$ & $35.65 \%$ & $28.22 \%$ \\
Bear Tracker & $33.92 \%$ & $51.98 \%$ & $108.98 \%$ & $70.08 \%$ & $52.07 \%$ \\
Call & $206.33 \%$ & $58.56 \%$ & $100.00 \%$ & $100.00 \%$ & $100.00 \%$ \\
Put & $114.96 \%$ & $71.49 \%$ & $100.00 \%$ & $100.00 \%$ & $100.00 \%$ \\
\hline
\end{tabular}

Table 3: Further risk measures: annual volatility, loss probability, and value at risk over a one year horizon for different pre-specified probabilities. 